Article

\title{
High Dietary Fructose Intake on Cardiovascular Disease Related Parameters in Growing Rats
}

\author{
SooYeon Yoo ${ }^{1}$, Hyejin Ahn ${ }^{1}$ and Yoo Kyoung Park ${ }^{1,2, *}$ \\ 1 Department of Medical Nutrition, Kyung Hee University, 1732 Deogyeong-daero, Giheung-gu, \\ Yongin 17104, Korea; sooyeon928@hanmail.net (S.Y.Y.); hjahn@khu.ac.kr (H.A.) \\ 2 Research Institute of Medical Nutrition, Kyung Hee University, 26, Kyungheedae-ro, Dongdaemun-gu, \\ Seoul 02447, Korea \\ * Correspondence: ypark@khu.ac.kr; Tel.: +82-31-201-3816; Fax: +82-31-203-3816
}

Received: 29 October 2016; Accepted: 15 December 2016; Published: 26 December 2016

\begin{abstract}
The objective of this study was to determine the effects of a high-fructose diet on cardiovascular disease (CVD)-related parameters in growing rats. Three-week-old female Sprague Dawley rats were randomly assigned to four experimental groups; a regular diet group (RD: fed regular diet based on AIN-93G, $n=8$ ), a high-fructose diet group (30Frc: fed regular diet with $30 \%$ fructose, $n=8$ ), a high-fat diet group (45Fat: fed regular diet with $45 \mathrm{kcal} \%$ fat, $n=8$ ) or a high fructose with high-fat diet group (30Frc $+45 \mathrm{Fat}$, fed diet 30\% fructose with $45 \mathrm{kcal} \%$ fat, $n=8$ ). After an eight-week treatment period, the body weight, total-fat weight, serum glucose, insulin, lipid profiles and pro-inflammatory cytokines, abdominal aortic wall thickness, and expressions of eNOS and ET-1 mRNA were analyzed. The result showed that total-fat weight was higher in the 30Frc, $45 \mathrm{Fat}$, and 30Frc $+45 \mathrm{Fat}$ groups compared to the RD group $(p<0.05)$. Serum triglyceride (TG) levels were highest in the 30Frc group than the other groups $(p<0.05)$. The abdominal aorta of 30Frc, 45Fat, and 30Frc +45 Fat groups had higher wall thickness than the RD group $(p<0.05)$. Abdominal aortic eNOS mRNA level was decreased in 30Frc, 45Fat, and 30Frc $+45 \mathrm{Fat}$ groups compared to the RD group $(p<0.05)$, and also 45Fat and 30Frc $+45 \mathrm{Fat}$ groups had decreased mRNA expression of eNOS compared to the 30Frc group $(p<0.05)$. ET-1 mRNA level was higher in 30Frc, 45Fat, and 30Frc $+45 \mathrm{Fat}$ groups than the RD group $(p<0.05)$. Both high fructose consumption and high fat consumption in growing rats had similar negative effects on CVD-related parameters.
\end{abstract}

Keywords: high fructose diet; cardiovascular disease (CVD); growing rat

\section{Introduction}

Sugar-sweetened beverages and processed foods are the main source of fructose [1]. According to The Korea National Health and Nutrition Examination Survey (KNHNES) [2], consumption of beverage products increased 3.7 folds from $1998(45.5 \pm 2.0 \mathrm{~g})$ to $2014(167.4 \pm 5.2 \mathrm{~g})$. Based on data collected from a 2010 study from The Korea Health Industry Development Institute (KHIDI) [3], consumption of sugar-sweetened beverages and processed foods in adolescents were higher than in the adult group.

Recently, a considerable volume of research was performed in both animals and humans dedicated to clarify the link between dietary fructose and health risk markers such as obesity and cardiovascular disease. Consumption of sugar-sweetened beverages has a positive correlation with body weight gain [4,5] in human, and in animals [6-8]. Bocarsly et al. [9] reported that rats fed with water containing high fructose corn syrup for eight weeks had increased body weight and body fat, and Crescenzo et al. [10] showed significant increases in body fat in rats that consumed fructose for eight weeks, with no significant difference in body weight. These observations are particularly important because accumulation of body fats leads to an increase of pro-inflammatory cytokines (TNF- $\alpha$, IL-6, PAI-1) [11]. 
In addition, a high fructose diet is known to lead hypertension and insulin resistance in animals [12,13]. Insulin resistance has been proposed as an underlying mechanism that links endothelial dysfunction factors such as endothelial nitric oxide synthase (eNOS) and Endothelin-1 (ET-1) [14]. Also, chronic exposure of dyslipidemia has a major effect on cardiovascular disease (CVD) [15]. De Castro et al. [16] reported that rats fed with a high fructose diet had significantly increased levels of in serum total-cholesterol and triglyceride. These changes are significantly associated with an increased incidence of cardiovascular disease [17].

Changes of CVD-related parameters in childhood is correlated with development into CVD which affects CVD risks later in life [18]. Although high-fructose affects CVD-related parameters in adult human and animals, these effects have not been investigated in adolescent or growing animals. Therefore, this study investigates the effects of a high-fructose diet and compares the results with a high-fat diet on CVD-related parameters in growing rats.

\section{Materials and Methods}

\subsection{Experimental Design and Diet}

The experimental protocol was approved by the Animal Care Use Review Committee of Kyung Hee University (IACUC, protocol number: KHP-2014-01-1). Three-week-old female Sprague-Dawley rats $(n=32)$ were provided by SLC, Inc. (Shizuoka, Japan). Rats were housed individually in polycarbonate cages in temperature-controlled rooms $\left(22 \pm 2{ }^{\circ} \mathrm{C}\right)$ with a relative humidity of $55 \% \pm 5 \%$, and a 12-h light/dark cycle. The rats were fed a pellet chow diet, and given water ad libitum for an adaptation period of 10 days. All rats were weighed weekly, and food intake was measured daily. After a 10-day adaption period, animals were randomized selected into the four different groups: regular diet group (RD) $(n=8)$ rats were fed an AIN-93G (D10012G, Research Diets Inc., New Brunswick, NJ, USA) diet, high fructose diet group (30Frc) $(n=8)$ rats were fed a 30\% fructose (D14010101, Research Diets Inc.) diet, high fat diet group (45Fat) $(n=8)$ rats were fed a $45 \mathrm{kcal} \%$ fat as soy bean oil and lard (D14010102, Research Diets Inc.) diet, and high fat diet with high fructose diet group (30Frc $+45 \mathrm{Fat})(n=8)$ rats were fed a diet with $30 \%$ fructose and $45 \mathrm{kcal} \%$ fat (D14010103, Research Diets Inc.). All animals were maintained on these diets ad libitum for eight weeks. Composition of experimental diets is shown in Table 1.

Table 1. Ingredient composition of experimental diets.

\begin{tabular}{ccccccccc}
\hline & \multicolumn{2}{c}{ RD } & \multicolumn{2}{c}{ 30Frc } & \multicolumn{2}{c}{ 45Fat } & \multicolumn{2}{c}{ 30Frc + 45Fat } \\
\hline \% & $\mathbf{g}$ & $\mathbf{k c a l}$ & $\mathbf{g}$ & $\mathbf{k c a l}$ & $\mathbf{g}$ & $\mathbf{k c a l}$ & $\mathbf{g}$ & $\mathbf{k c a l}$ \\
\hline Protein & 20 & 20 & 20 & 20 & 24 & 20 & 24 & 20 \\
Carbohydrate & 64 & 64 & 64 & 64 & 41 & 35 & 41 & 35 \\
Fat & 7 & 16 & 7 & 16 & 24 & 45 & 24 & 45 \\
Total & & 100 & & 100 & & 100 & & 100 \\
kcal/gm & 4.0 & & 4.0 & & 4.8 & & 4.8 & \\
\hline Ingredient & $\mathbf{g}$ & $\mathbf{k c a l}$ & $\mathbf{g}$ & $\mathbf{k c a l}$ & $\mathbf{g}$ & $\mathbf{k c a l}$ & $\mathbf{g}$ & $\mathbf{k c a l}$ \\
\hline Casein, 80 Mesh & 200 & 800 & 200 & 800 & 200 & 800 & 200 & 800 \\
L-Cystine & 3 & 12 & 3 & 12 & 3 & 12 & 3 & 12 \\
Corn Starch & 397.5 & 1590 & 229.5 & 918 & 137 & 548 & 0 & 0 \\
Maltodextrin 10 & 132 & 528 & 100 & 400 & 100 & 400 & 37 & 148 \\
Sucrose & 100 & 400 & 0 & 0 & 100 & 400 & 0 & 0 \\
Fructose & 0 & 0 & 300 & 1200 & 0 & 0 & 300 & 1200 \\
Cellulose & 50 & 0 & 50 & 0 & 50 & 0 & 50 & 0 \\
Soybean Oil & 70 & 630 & 70 & 630 & 26 & 234 & 26 & 234 \\
t-Butylhydroquinone & 0.014 & 0 & 0.014 & 0 & 0.014 & 0 & 0.014 & 0 \\
Lard & 0 & 0 & 0 & 0 & 174 & 1566 & 174 & 1566 \\
Mineral Mix & 35 & 0 & 35 & 0 & 35 & 0 & 35 & 0 \\
Vitamin Mix & 10 & 40 & 10 & 40 & 10 & 40 & 10 & 40 \\
Choline Bitartrate & 2.5 & 0 & 2.5 & 0 & 2.5 & 0 & 2.5 & 0 \\
Total & 1000 & 4000 & 1000 & 4000 & 837.5 & 4000 & 837.5 & 4000 \\
\hline
\end{tabular}

RD: rats received a regular diet based on AIN-93G (4.0 kcal/g diet); 30Frc: rats received a $30 \%$ fructose-diet based on regular diet $(4.0 \mathrm{kcal} / \mathrm{g}$ diet); $45 \mathrm{Fat}$ : rats received a $45 \mathrm{kcal} \%$ fat-diet $(4.8 \mathrm{kcal} / \mathrm{g}$ diet); $30 \mathrm{Frc}+45 \mathrm{Fat}$ : rats received a $45 \mathrm{kcal} \%$ fat -diet with $30 \%$ fructose ( $4.8 \mathrm{kcal} / \mathrm{g}$ diet). 


\subsection{Body Weight, Food Consumption, and Fat Mass}

Body weights and food consumption were measured weekly and daily, respectively. The food efficiency ratio (FER) was calculated using the following formula: (weight gain (g)/week)/(food consumed (kcal)/week). At the end of the eight-week experimental period, total fat was removed and weighed immediately after killing. The total fat was measured by combining the weight of subcutaneous fat and visceral fat.

\subsection{Analysis of Blood Parameters}

Blood was collected at the end of experiment, following a 12-h overnight fast. Rats were anesthetized with a small amount of ethyl ether, and blood samples were taken by heart puncture. Blood samples were immediately collected into serum-separating tubes (SST) and were centrifuged at $3000 \mathrm{rpm}$ for $15 \mathrm{~min}$ at $4{ }^{\circ} \mathrm{C}$. Serum was stored at $-70{ }^{\circ} \mathrm{C}$ until used in assays. Serum triglyceride (TG), Total cholesterol (T-Chol), HDL-cholesterol (HDL-C), and glucose levels were determined using commercial kits (Asan Co. Ltd., Seoul, Korea). Atherogenic Index (AI) was calculated using the following formula: $\mathrm{AI}=$ (total cholesterol $-\mathrm{HDL}$-cholesterol $) / \mathrm{HDL}$-cholesterol. Serum Insulin concentrations were determined using an ELISA rat/mouse insulin kit (ALPCO Diagnostics, Salem, $\mathrm{NH}, \mathrm{USA}$ ). Insulin resistance was calculated by a homeostasis assessment model (HOMA-IR) and calculated from fasting insulin and glucose concentration according to the formula: (fasting insulin $(\mathrm{ng} / \mathrm{mL}) \times$ fasting glucose $(\mathrm{mg} / \mathrm{dL})) / 22.5$. Quantitative insulin sensitivity check index (QUICKI) was also calculated using the following formula: QUICKI $=1 /(\log$ fasting insulin $(\mathrm{mg} / \mathrm{dL})+\log$ fasting glucose $(\mathrm{mg} / \mathrm{dL})$ ). Pro-inflammatory cytokines (TNF- $\alpha$, IL-6, and PAI-1) were measured in duplicate using Milipore's MILLIPLEX rat CVD cytokine panel (Millipore, Billerica, MA, USA).

\subsection{Analysis of Abdominal Aorta}

Abdominal aorta samples were obtained after rats were sacrificed at the end of experiment. The abdominal aortas were fixed in a $4 \%$ formalin solution, followed by sequential dehydration ( $70 \%$ ethanol, $100 \%$ ethanol, and acetone), xylene clearance, and paraffin embedding. The paraffin-embedded aortas were cut into 5-micron slices with a microtome (820 II; Reichert-Jung, Bensheim, Germany). Then the sliced aortas were stained with Harris hematoxylin and eosinY ( $\mathrm{H} \& \mathrm{E})$. Wall thickness and lumen diameter of abdominal aortas were determined on five isotropic uniform random sections per animal at a magnification of 500:1 and phase contrast. All sections were photographed using a microscope (model Axiovert S100, Zeiss, Oberkochen, Germany) connected to a camera (model AxioCam, Zeiss) and MetaMorph software (Molecular Devices, Sunnyvale, CA, USA). Wall thickness and lumen diameter were determined as the mean of the minimal and maximal value.

\subsection{Quantitative Real-Time Polymerase Chain Reaction (PCR)}

Total RNA was extracted from abdominal aorta using an RNeasy mini kit (Qiagen, Gaithersburg, MD, USA) according to the manufacturer's instructions. Real-time quantitative PCR was performed using an Applied Bio-systems (Applied Bio-systems, Foster City, CA, USA); $1 \mu \mathrm{L}$ with $100 \mathrm{nM}$ of each primer (forward and reverse) reaction consisted of $10 \mu \mathrm{L}$ of the SYBR Green Super-mix (iQ SYBR Green Super-mix, Bio-Rad Laboratories Inc. Hercules, CA, USA), according to the manufacturer's instructions. Thermal cycling was initiated by denaturation at $95{ }^{\circ} \mathrm{C}$ for $10 \mathrm{~min}$, followed by 40 cycles of $95{ }^{\circ} \mathrm{C}$ for $15 \mathrm{~s}$ and $60{ }^{\circ} \mathrm{C}$ for $30 \mathrm{~s}$, then an annealing step was performed at adequate temperature in function of the primers and $72{ }^{\circ} \mathrm{C}$ for $30 \mathrm{~s}$ for extension. After the final cycle, melting curves were monitored from 55 to $65{ }^{\circ} \mathrm{C}$ $\left(0.05^{\circ} \mathrm{C} / \mathrm{s}\right)$. The primer sequences were: rat eNOS, $5^{\prime}$-CAACAAACCGAGGCAATCTTC- $3^{\prime}$ (forward), 5'-CCCGGCCAGCGTAGCT-3' (reverse), and rat ET-1， 5'-TGGACATCATCTGGGTCAACA-3' (forward), 5'-GCTTAGACCTAGAAGGGCTTCCTAGT-3' (reverse), and rat glyceraldehyde 
3'-phosphate dehydrogenase (GAPDH), 5'-TGGCCTCCAAGGAGTAAGAAAC-3' (forward), $5^{\prime}$-GGCCTCTCTCTTGCTCTCAGTATC-3' (reverse). The detected genes were eNOS and ET-1.

\subsection{Statistical Analysis}

All measurements were performed in duplicate, and statistical calculations were performed with Statistical Package for the social Sciences (SPSS, version 20.0, IBM Corp., Armonk, NY, USA) software. All data were presented as mean \pm SD. Differences in measured parameters among the experimental groups were analyzed by the one-way ANOVA and Duncan's multiple range tests. The respective effects of operation and diet were analyzed by two-way ANOVA. The differences were considered to be significant when the $p$ value was less than 0.05 .

\section{Results}

\subsection{Body Weights, Food Intakes, Calorie Intakes, and Food Efficiency Ratios}

The effect of the diet on body weight, body weight gain, food intake, calorie intake, and food efficiency ratio is shown in Table 2.

Table 2. Body weights, food intakes, calorie intakes, and food efficiency ratio.

\begin{tabular}{ccccc}
\hline & $\begin{array}{c}\text { RD } \\
(\boldsymbol{n}=\mathbf{8})\end{array}$ & $\begin{array}{c}\text { 30Frc } \\
(\boldsymbol{n}=\mathbf{8})\end{array}$ & $\begin{array}{c}\text { 45Fat } \\
(\boldsymbol{n}=\mathbf{8})\end{array}$ & $\begin{array}{c}\text { 30Frc + 45Fat } \\
(\boldsymbol{n}=\mathbf{8})\end{array}$ \\
\hline Initial body weight (g) & $74.6 \pm 2.6$ & $74.9 \pm 5.0$ & $74.5 \pm 4.71$ & $74.4 \pm 4.1$ \\
Final body weight (g) & $251.3 \pm 9.6^{\mathrm{b}}$ & $263.3 \pm 15.0^{\mathrm{a}, \mathrm{b}}$ & $278.1 \pm 22.1^{\mathrm{a}}$ & $277.2 \pm 16.6^{\mathrm{a}}$ \\
Weight gain (g) & $177.2 \pm 9.8^{\mathrm{b}}$ & $188.0 \pm 13.4^{\mathrm{a}, \mathrm{b}}$ & $204.3 \pm 22.6^{\mathrm{a}}$ & $201.9 \pm 17.7^{\mathrm{a}}$ \\
Food intake (g/day) & $12.5 \pm 0.8^{\mathrm{a}}$ & $13.2 \pm 0.9^{\mathrm{a}}$ & $11.3 \pm 0.9^{\mathrm{b}}$ & $11.5 \pm 0.8^{\mathrm{b}}$ \\
Calorie intake (kcal/day) & $49.8 \pm 2.9$ & $52.4 \pm 4.4$ & $53.8 \pm 4.6$ & $54.7 \pm 4.7$ \\
Food efficiency ratio & $0.05 \pm 0.00$ & $0.05 \pm 0.00$ & $0.05 \pm 0.01$ & $0.05 \pm 0.00$ \\
\hline
\end{tabular}

All values are presented as means \pm standard deviation (SD). RD: rats received a regular diet based on AIN-93G (4.0 kcal/g diet); 30Frc: rats received a 30\% fructose-diet based on control-diet $(4.0 \mathrm{kcal} / \mathrm{g}$ diet); 45Fat: rats received a $45 \mathrm{kcal} \%$ fat-diet $(4.8 \mathrm{kcal} / \mathrm{g}$ diet); $30 \mathrm{Frc}+45 \mathrm{Fat}$ : rats received a $45 \mathrm{kcal} \%$ fat-diet with $30 \%$ fructose $(4.8 \mathrm{kcal} / \mathrm{g}$ diet$) ;$ Food efficiency ratio = (weight gain $(\mathrm{g}) /$ week $) /($ food consumed $(\mathrm{kcal}) /$ week$)$. Statistical differences between the experimental groups were based on one-way ANOVA and Duncan's multiple range tests at $p<0.05$. Means with different alphabetical superscripts are significantly different $(p<0.05)$.

The initial body weights were not significantly different among the experimental groups. Feeding of high fat diet groups (45Fat, 30Frc $+45 \mathrm{Fat}$ ) resulted in a significantly higher body weight than the RD and 45Fat groups $(278.1 \pm 22.1 \mathrm{~g}, 277.2 \pm 16.6 \mathrm{~g}$ vs. $251.3 \pm 9.6 \mathrm{~g}, 263.3 \pm 15.0 \mathrm{~g}, p<0.05)$. The food intake was significantly higher in the RD (12.5 $\pm 0.8 \mathrm{~g} /$ day $)$ and 30Frc (13.2 $\pm 1.0 \mathrm{~g} /$ day) groups compared to that of $45 \mathrm{Fat}(11.3 \pm 0.9 \mathrm{~g} /$ day $)$ and $30 \mathrm{Frc}+45 \mathrm{Fat}(11.5 \pm 0.8 \mathrm{~g} /$ day $)$ groups $(p<0.05)$. However, total calorie intakes and food efficiency ratios were not significantly different among the experimental groups. Total calorie was calculated from food intake $(\mathrm{g}) \times$ calorie density $(\mathrm{kcal} / \mathrm{g})$.

\subsection{Total-Fat Weights}

The total-fat weights of the experimental groups are shown in Figure 1. 


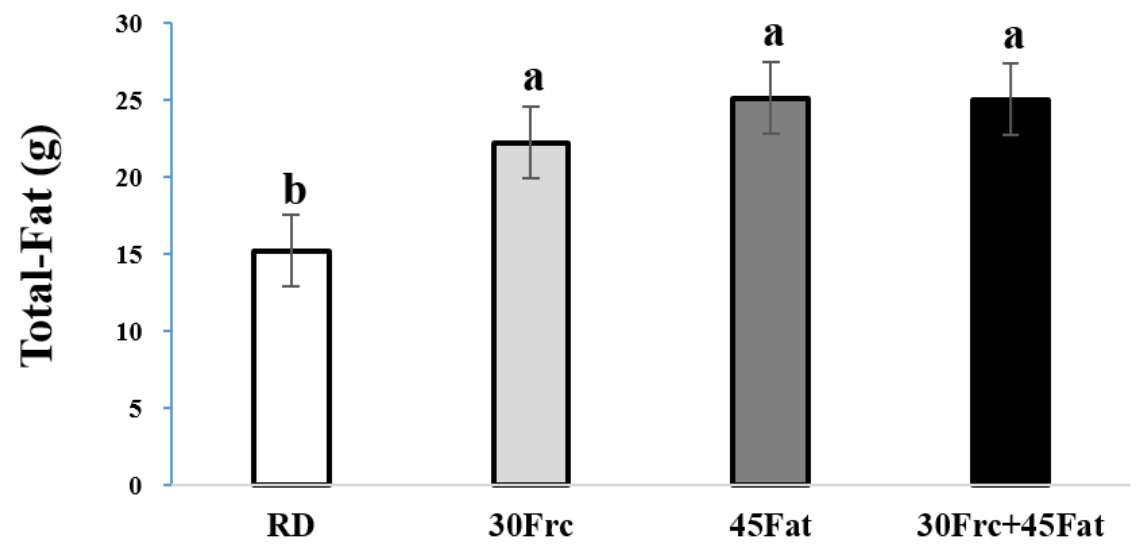

Figure 1. Total-fat weight in the experimental groups. RD: rats received a regular diet based on AIN-93G (4.0 kcal/g diet); 30Frc: rats received a 30\% fructose-diet based on control-diet ( $4.0 \mathrm{kcal} / \mathrm{g}$ diet); 45Fat: rats a received $45 \mathrm{kcal} \%$ fat-diet ( $4.8 \mathrm{kcal} / \mathrm{g}$ diet); $30 \mathrm{Frc}+45 \mathrm{Fat}$ : rats received a $45 \mathrm{kcal} \%$ fat-diet with $30 \%$ fructose $(4.8 \mathrm{kcal} / \mathrm{g}$ diet). Statistical differences between the experimental groups were based on one-way ANOVA and Duncan's multiple range tests at $p<0.05$. Means with different alphabetical letters are significantly different $(p<0.05)$.

The average total-fat weights were $15.2 \pm 3.6,22.2 \pm 3.8,25.1 \pm 3.5$, and $25.0 \pm 2.4 \mathrm{~g}$ in the RD, $30 \mathrm{Frc}$, 45Fat, and 30Frc $+45 \mathrm{Fat}$ groups. The total-fat weights were significantly higher in 30Frc, 45Fat, and 30Frc +45 Fat groups than the RD group $(p<0.05)$.

\subsection{Serum Levels of Glucose and Insulin, HOMA-IR, and QUICKI}

The blood glucose and insulin levels, HOMA-IR, and QUICKI are shown in Table 3. The serum glucose and insulin levels did not differ among the experimental groups. Also, no differences were observed in HOMA-IR and QUICKI among groups.

Table 3. Serum levels of glucose and insulin.

\begin{tabular}{ccccc}
\hline & $\begin{array}{c}\text { RD } \\
(\boldsymbol{n}=\mathbf{8})\end{array}$ & $\begin{array}{c}\text { 30Frc } \\
(\boldsymbol{n}=\mathbf{8})\end{array}$ & $\begin{array}{c}\text { 45Fat } \\
(\boldsymbol{n}=\mathbf{8})\end{array}$ & $\begin{array}{c}\text { 30Frc + 45Fat } \\
(\boldsymbol{n}=\mathbf{8})\end{array}$ \\
\hline Glucose (mg/dL) & $143.6 \pm 10.3$ & $142.0 \pm 9.2$ & $141.4 \pm 14.9$ & $136.6 \pm 15.8$ \\
Insulin (ng/mL) & $1.2 \pm 1.4$ & $2.2 \pm 1.7$ & $0.9 \pm 0.3$ & $1.3 \pm 0.9$ \\
HOMA-IR & $8.1 \pm 9.1$ & $12.7 \pm 11.7$ & $5.9 \pm 2.4$ & $8.3 \pm 6.2$ \\
QUICKI & $0.5 \pm 0.07$ & $0.4 \pm 0.07$ & $0.5 \pm 0.05$ & $0.5 \pm 0.07$ \\
\hline
\end{tabular}

All values are presented as means \pm standard deviation (SD). RD: rats received a regular diet based on AIN-93G (4.0 kcal/g diet); 30Frc: rats received a 30\% fructose-diet based on control-diet (4.0 kcal/g diet); 45Fat: rats received a $45 \mathrm{kcal} \%$ fat-diet $(4.8 \mathrm{kcal} / \mathrm{g}$ diet); $30 \mathrm{Frc}+45 \mathrm{Fat}$ : rats received a $45 \mathrm{kcal} \%$ fat-diet with $30 \%$ fructose $(4.8 \mathrm{kcal} / \mathrm{g}$ diet), HOMA-IR: homoeostasis model assessment of insulin resistance was calculated by (fasting insulin $(\mathrm{ng} / \mathrm{mL})$; QUICKI: $1 /(\log ($ fasting insulin $\mathrm{ng} / \mathrm{mL})+\log ($ fasting glucose $\mathrm{mg} / \mathrm{dL})) \times$ fasting glucose $(\mathrm{mg} / \mathrm{dL})) / 22.5$. There were no significant differences among groups according to ANOVA and Duncan's multiple range tests.

\subsection{Serum Levels of Lipid Profiles}

The serum lipid profile levels are shown in Table 4. Serum Total-C, HDL-C, and atherogenic index were not different among groups. However, the serum TG levels in the 30Frc group $(108.6 \pm 25.2 \mathrm{mg} / \mathrm{dL})$ were significantly higher than the RD, 45Fat, and 30Frc +45 Fat groups $(71.4 \pm 19.8,88.6 \pm 26.9$, and $93.9 \pm 24.1 \mathrm{mg} / \mathrm{dL}$, respectively) $(p<0.05)$. 
Table 4. Serum levels of lipid profiles.

\begin{tabular}{ccccc}
\hline & $\begin{array}{c}\text { RD } \\
(\boldsymbol{n}=\mathbf{8})\end{array}$ & $\begin{array}{c}\text { 30Frc } \\
(\boldsymbol{n}=\mathbf{8})\end{array}$ & $\begin{array}{c}\text { 45Fat } \\
(\boldsymbol{n}=\mathbf{8})\end{array}$ & $\begin{array}{c}\text { 30Frc + 45Fat } \\
(\boldsymbol{n}=\mathbf{8})\end{array}$ \\
\hline TG $(\mathrm{mg} / \mathrm{dL})$ & $71.4 \pm 19.8^{\mathrm{b}}$ & $108.6 \pm 25.2^{\mathrm{a}}$ & $88.6 \pm 26.9^{\mathrm{a}, \mathrm{b}}$ & $93.9 \pm 24.1^{\mathrm{a}, \mathrm{b}}$ \\
Total-C $(\mathrm{mg} / \mathrm{dL})$ & $107.9 \pm 19.7$ & $114.6 \pm 17.5$ & $97.8 \pm 15.4$ & $96.3 \pm 18.4$ \\
HDL-C (mg/dL) & $98.1 \pm 12.4$ & $103.8 \pm 10.9$ & $92.1 \pm 13.4$ & $91.8 \pm 14.7$ \\
AI & $0.09 \pm 0.07$ & $0.10 \pm 0.05$ & $0.06 \pm 0.03$ & $0.05 \pm 0.05$ \\
\hline
\end{tabular}

All values are presented as means \pm standard deviation (SD). RD: rats received a regular diet based on AIN-93G (4.0 kcal/g diet); 30Frc: rats received a 30\% fructose-diet based on control-diet $(4.0 \mathrm{kcal} / \mathrm{g}$ diet); 45Fat: rats received a $45 \mathrm{kcal} \%$ fat-diet $(4.8 \mathrm{kcal} / \mathrm{g}$ diet); $30 \mathrm{Frc}+45 \mathrm{Fat}$ : rats received a $45 \mathrm{kcal} \%$ fat-diet with $30 \%$ fructose $(4.8 \mathrm{kcal} / \mathrm{g}$ diet); TG: Triglyceride; Total-C: Total cholesterol; AI: Atherogenic index $=($ total cholesterol - HDL-cholesterol $) /$ HDL-cholesterol. Statistical difference between the experimental groups were based on one-way ANOVA and Duncan's multiple range tests at $p<0.05$. Means with different alphabetical superscripts are significantly different $(p<0.05)$.

\subsection{Serum Levels of Pro-Inflammatory Cytokines}

The serum pro-inflammatory cytokines levels are shown in Table 5. The mean levels of serum pro-inflammatory cytokines levels (TNF- $\alpha$, IL-6, PAI-1) did not differ among the experimental groups.

Table 5. Serum levels of pro-inflammatory cytokines.

\begin{tabular}{ccccc}
\hline & $\begin{array}{c}\text { RD } \\
(\boldsymbol{n}=\mathbf{8})\end{array}$ & $\begin{array}{c}\text { 30Frc } \\
(\boldsymbol{n}=\mathbf{8})\end{array}$ & $\begin{array}{c}\text { 45Fat } \\
(\boldsymbol{n}=\mathbf{8})\end{array}$ & $\begin{array}{c}\text { 30Frc }+ \text { 45Fat } \\
(\boldsymbol{n}=\mathbf{8})\end{array}$ \\
\hline TNF- $\alpha(\mathrm{pg} / \mathrm{mL})$ & $55.1 \pm 4.9$ & $51.5 \pm 5.5$ & $47.0 \pm 4.8$ & $48.3 \pm 10.9$ \\
$\mathrm{IL}-6(\mathrm{pg} / \mathrm{mL})$ & $11.6 \pm 4.2$ & $18.2 \pm 11.6$ & $12.6 \pm 4.0$ & $15.5 \pm 8.3$ \\
PAI-1 $(\mathrm{pg} / \mathrm{mL})$ & $100.8 \pm 13.3$ & $101.5 \pm 9.4$ & $96.0 \pm 4.8$ & $99.4 \pm 20.5$ \\
\hline
\end{tabular}

All values are presented as means \pm standard deviation (SD). RD: rats received a regular diet based on AIN-93G (4.0 kcal/g diet); 30Frc: rats received a 30\% fructose-diet based on control-diet (4.0 kcal/g diet); 45Fat: rats received a $45 \mathrm{kcal} \%$ fat-diet ( $4.8 \mathrm{kcal} / \mathrm{g}$ diet); $30 \mathrm{Frc}+45 \mathrm{Fat}$ : rats received a $45 \mathrm{kcal} \%$ fat-diet with $30 \%$ fructose (4.8 kcal/g diet); TNF- $\alpha$ : Tumor Necrosis $\alpha$; IL-6: Interleukin-6; PAI-1: Plasminogen activator inhibitor-1. There were no significant differences among groups according to ANOVA and Duncan's multiple range tests.

\subsection{Analysis of Abdominal Aorta Wall Thickness and Lumen Diameter}

The abdominal aorta wall thickness and lumen diameter are shown in Table 6 and Figure 2. The aorta wall thickness was significantly increased in $30 \mathrm{Frc}$, 45Fat, and $30 \mathrm{Frc}+45 \mathrm{Fat}$ groups $(23.6 \pm 0.9 \mu \mathrm{m}, 23.7 \pm 2.8 \mu \mathrm{m}$, and $22.5 \pm 2.2 \mu \mathrm{m}$, respectively, $p<0.05)$ than the RD group $(18.5 \pm 0.5 \mu \mathrm{m})$. The lumen diameter was not different among the groups. The wall thickness:lumen ratio was increased in 30Frc, 45Fat and 30Frc $+45 \mathrm{Fat}$ groups $(0.096 \pm 0.001 \mu \mathrm{m}, 0.098 \pm 0.014 \mu \mathrm{m}$, and $0.085 \pm 0.005 \mu \mathrm{m}$, respectively, $p<0.05)$ than the RD group $(0.061 \pm 0.009 \mu \mathrm{m})$.

Table 6. Abdominal aorta wall thickness and lumen diameter.

\begin{tabular}{|c|c|c|c|c|}
\hline & $\begin{array}{c}\text { RD } \\
(n=8)\end{array}$ & $\begin{array}{c}\text { 30Frc } \\
(n=8)\end{array}$ & $\begin{array}{l}\text { 45Fat } \\
(n=8)\end{array}$ & $\begin{array}{c}30 \mathrm{Frc}+45 \mathrm{Fat} \\
(n=8)\end{array}$ \\
\hline Wall thickness $(\mu \mathrm{m})$ & $18.5 \pm 0.5^{b}$ & $23.6 \pm 0.9^{a}$ & $23.7 \pm 2.8^{\mathrm{a}}$ & $22.5 \pm 2.2^{\mathrm{a}}$ \\
\hline Lumen diameter $(\mu \mathrm{m})$ & $306.8 \pm 54.4$ & $248.4 \pm 25.1$ & $243.9 \pm 29.4$ & $266.9 \pm 29.0$ \\
\hline $\begin{array}{c}\text { Wall thickness/ } \\
\text { Lumen ratio }(\mu \mathrm{m} / \mu \mathrm{m})\end{array}$ & $0.061 \pm 0.009^{b}$ & $0.096 \pm 0.001^{\mathrm{a}}$ & $0.098 \pm 0.014^{a}$ & $0.085 \pm 0.005^{\mathrm{a}}$ \\
\hline \multicolumn{5}{|c|}{$\begin{array}{l}\text { All values are presented as means } \pm \text { standard deviation (SD). RD: rats received a regular diet based on AIN-93G } \\
\text { ( } 4.0 \mathrm{kcal} / \mathrm{g} \text { diet); 30Frc: rats received a } 30 \% \text { fructose-diet based on control-diet }(4.0 \mathrm{kcal} / \mathrm{g} \text { diet); } 45 \mathrm{Fat} \text { rats } \\
\text { received a } 45 \mathrm{kcal} \% \text { fat-diet }(4.8 \mathrm{kcal} / \mathrm{g} \text { diet }) ; 30 \mathrm{Frc}+45 \mathrm{Fat} \text { rats received a } 45 \mathrm{kcal} \% \text { fat-diet with } 30 \% \text { fructose } \\
\text { ( } 4.8 \mathrm{kcal} / \mathrm{g} \text { diet). Statistical differences between the experimental groups were based on one-way ANOVA } \\
\text { and Duncan's multiple range tests at } p<0.05 \text {. Means with different alphabetical superscripts are significantly } \\
\text { different }(p<0.05) \text {. }\end{array}$} \\
\hline
\end{tabular}




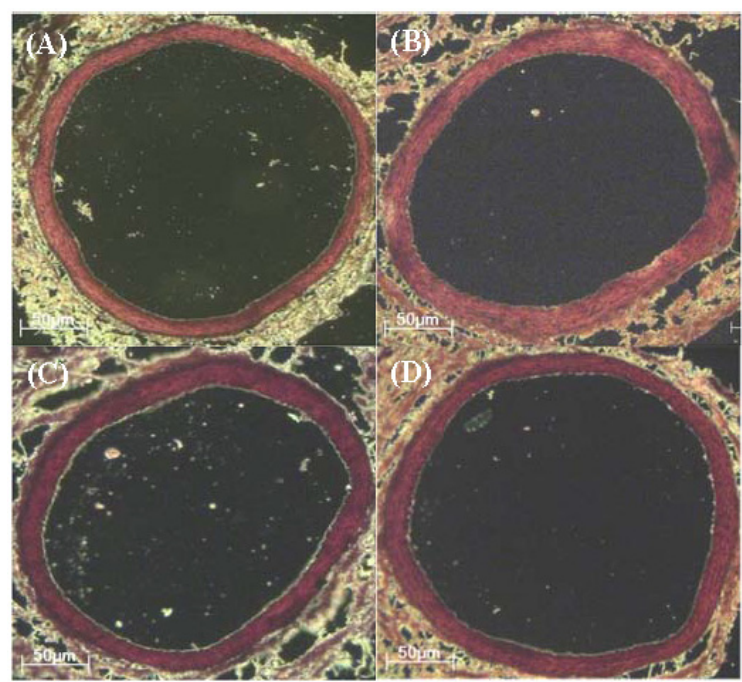

Figure 2. Abdominal aortic wall thickness and lumen diameter taken at eight weeks, pertaining to the respective groups (A) RD; (B) 30Frc; (C) 45Fat; (D) 30Frc + 45Fat. Hematoxylin and eosin (H \& E) stained abdominal aorta $\times 500$. Magnification bars $50 \mu \mathrm{m}$. RD: rats received a regular diet based on AIN-93G (4.0 kcal/g diet); 30Frc: rats received a 30\% fructose-diet based on control-diet ( $4.0 \mathrm{kcal} / \mathrm{g}$ diet); 45Fat: rats received a $45 \mathrm{kcal} \%$ fat-diet $(4.8 \mathrm{kcal} / \mathrm{g}$ diet); $30 \mathrm{Frc}+45 \mathrm{Fat}$ : rats received a $45 \mathrm{kcal} \%$ fat-diet with $30 \%$ fructose $(4.8 \mathrm{kcal} / \mathrm{g}$ diet $)$.

\subsection{Abdominal Aortic eNOS and ET-1 mRNA Expression Measured by qRTPC}

The abdominal aortic eNOS and ET-1 mRNA expression of the experimental groups are shown in Figures 3 and 4. The aortic eNOS mRNA expression was significantly decreased in 45Fat and $30 \mathrm{Frc}+45 \mathrm{Fat}$ groups $(0.3 \pm 0.06$ and $0.4 \pm 0.07$, respectively, $p<0.05)$ compared to the RD and 30Frc groups $(1.0 \pm 0.00$ and $0.7 \pm 0.05$, respectively). Also, for the $30 \mathrm{Frc}$ group that was fed the high fructose diet constantly, the aortic eNOS mRNA expression was significantly decreased compared to the RD group $(p<0.05)$. The aortic ET-1 mRNA expression of the 30Frc $+45 \mathrm{Fat}$ group was the highest among the four groups $(10.3 \pm 1.8$ vs. $1.0 \pm 0.4,3.3 \pm 0.3$, and $7.4 \pm 0.7$, respectively, for the RD, 30Frc, and 45Fat groups, $p<0.05)$.

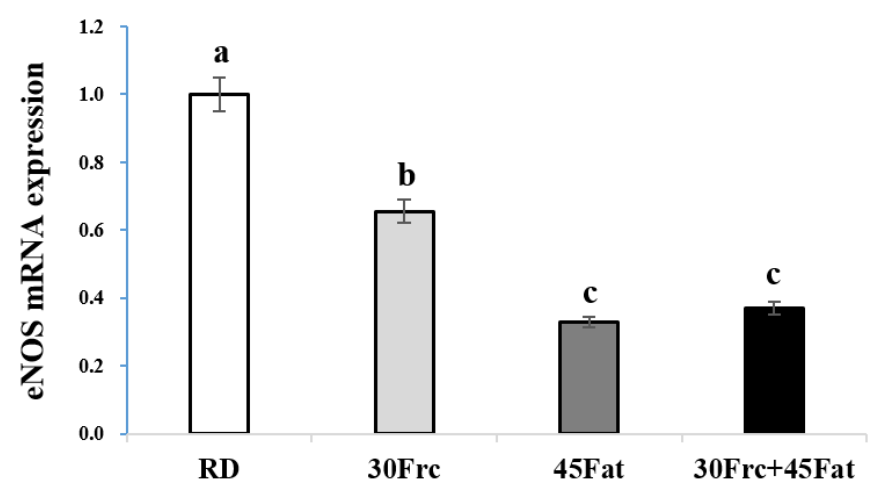

Figure 3. Aortic eNOS mRNA expression measured by quantitative real-time polymerase chain reaction (qRTPCR). RD: rats received a regular diet based on AIN-93G (4.0 kcal/g diet); 30Frc: rats received a $30 \%$ fructose-diet based on control-diet $(4.0 \mathrm{kcal} / \mathrm{g}$ diet); $45 \mathrm{Fat}$ : rats received a $45 \mathrm{kcal} \%$ fat-diet (4.8 kcal/g diet); 30Frc + 45Fat: rats received a $45 \mathrm{kcal} \%$ fat-diet with $30 \%$ fructose $(4.8 \mathrm{kcal} / \mathrm{g}$ diet). Statistical differences between the experimental groups were based on one-way ANOVA and Duncan's multiple range tests at $p<0.05$. Means with different alphabetical letters are significantly different $(p<0.05)$. 


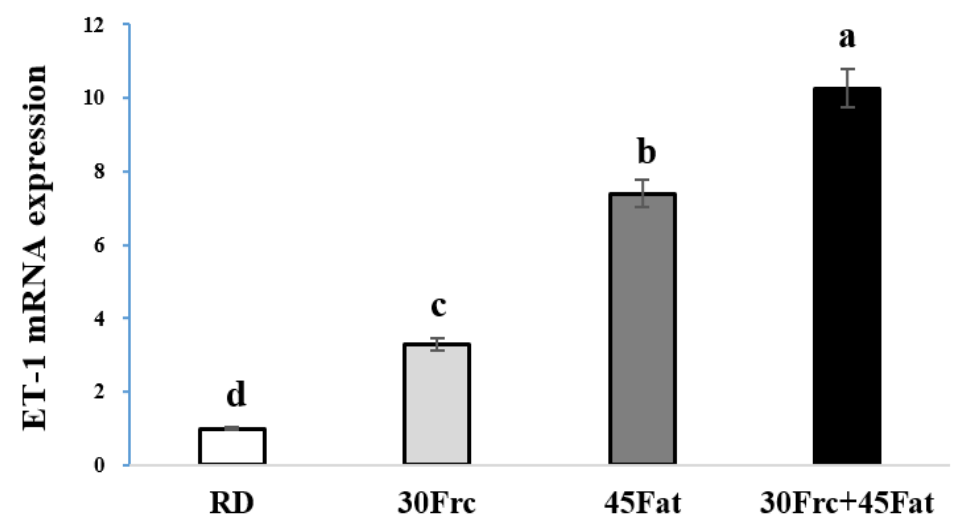

Figure 4. Aortic ET-1 mRNA expression measured by qRTPCR. RD: rats received a regular diet based on AIN-93G (4.0 kcal/g diet); 30Frc: rats received a 30\% fructose-diet based on control-diet (4.0 kcal/g diet); 45 Fat: rats received a $45 \mathrm{kcal} \%$ fat-diet $(4.8 \mathrm{kcal} / \mathrm{g}$ diet $) ; 30 \mathrm{Frc}+45 \mathrm{Fat}$ : rats received a $45 \mathrm{kcal} \%$ fat-diet with $30 \%$ fructose $(4.8 \mathrm{kcal} / \mathrm{g}$ diet $)$. Statistical differences between the experimental groups were based on one-way ANOVA and Duncan's multiple range tests at $p<0.05$. Means with different alphabetical letters are significantly different $(p<0.05)$.

\section{Discussion}

The purpose of this study was to determine the effects of a high-fructose diet on cardiovascular disease (CVD)-related parameters in growing rats.

It was known that rats fed high-fat diets increased body weight and body fat $[19,20]$. The present study showed that the consumption of a high-fat diet (45Fat, 30Frc $+45 \mathrm{Fat})$ in growing rats significantly increased body weight and body fat compared to regular diet and high-fructose diet groups. The high-fructose diet did not affect the body weight, whereas it significantly increased the weight of body fat compared to the regular diet fed group. The previous study reported that rats fed with the high-fructose diet (60\%) for 10 weeks increased body weight [7]. However, Crescenzo et al. [10] showed increased white adipose tissue (WAT) in rats fed fructose $(60 \%)$, despite no difference in body weight gain. An increase in body weight alone does not necessarily indicate obesity, it has to be considered along with other factors, such as changes in body composition [21]. The increase in body fat reflected the obesogenic property. This suggests that obesity can be induced by high-fructose diet, as well as high-fat diet.

Dyslipidemia, especially hypertriglyceridemia and insulin resistance are major factors associated with CVD in rats fed a high-fructose diet $(60 \%)$ [22,23]. Our data showed that the 30Frc group had significantly increased serum TG levels compared to the other groups. In the liver, fructose is divided into glyceraldehyde and dihydroxyacetone phosphate, ultimately becoming triglyceride [24]. Therefore, exposure to high fructose levels to rapidly increased levels of triglyceride synthesis. We consider that excessive fructose consumption can lead to dyslipidemia and obesity; these changes are caused CVD.

Insulin resistance is closely linked to dyslipimenia [25]. Many previous studies have reported that the high-fructose diet can induce hyperglycemia (35\%,66\%) [26,27]. However, this study showed no difference in serum glucose and insulin levels. The previous study suggested that although fructose does not appear to acutely increase insulin levels, chronic exposure seems to indirectly cause insulin resistance and obesity through other mechanisms, such as GLUT5 fructose transporters and inflammation [28]. Iida et al. [29] reported that rats fed $40 \%$ fructose for eight weeks displayed no difference in serum insulin levels. Another study showed that rats fed with $66 \%$ fructose for two weeks increased plasma TG, even though there was no change in plasma glucose, insulin, and body weight [30]. Increased triglyceride levels in response to high-fructose diet could have resulted in insulin resistance by reducing the insulin signaling pathway [27]. Our data, together with the previously 
established literature showed, suggest that chronic exposure to a high-fructose diet can result in hypertriglycemia, and that this change could cause insulin resistance.

Enlarged body fat induces the expression of pro-inflammatory cytokines [11]. A previous study reported that a high fructose diet can increase hepatic mRNA expression of TNF- $\alpha$, IL-6, and the weight of epididymal fat pads in rats [31]. However, the present study had shown that rats fed a high-fructose diet significantly increased the total body fat, but the serum pro-inflammatory cytokines (TNF- $\alpha$, IL-6, PAI-1) did not change in between groups. Chronic inflammation is an important pathogenic factor in the development of CVD [32,33]. Large amounts of markers for inflammatory cytokines can be released from the adipose tissue [34]. Yudkin et al. [35] reported that adipose tissue can also synthesize pro-inflammatory cytokines such as TNF- $\alpha$ and IL-6. In this way, increased body fat itself promotes inflammation. According to this hypothesis, high fructose consumption leads to increased body fat and obesity, which can cause changes to inflammatory cytokines. In the present study we showed that rats fed a high-fructose diet significantly increased their total-fat weight, although the serum pro-inflammatory cytokines did not change.

Changes in the aorta wall thickness is significantly associated with serum lipid profiles and hypertension, which begins in childhood and may develop into cardiovascular disease [35-38]. According to a previous study, the tunica intima-media layer was increased in the high-fructose diet group [31]. Autopsy studies have reported that the first atherosclerotic lesions actually begin to develop in the abdominal aorta [39]. Therefore, we chose the abdominal aorta to conduct the present experiment. In the present study we showed that the abdominal aorta of high-fructose diet and high fat diet rats were thicker in comparison to the regular diet group. We consider that high-fructose consumption as well as high-fat consumption, can have a significant effect on abdominal aorta wall thickness in the growing rats. These early changes can possibly lead to endothelial dysfunction.

Endothelial dysfunction is a systemic disorder in the pathogenesis of atherosclerosis [40], which plays an important role in hypertension [41] and CVD [42]. The endothelium maintains the balance between vasoconstriction and vasodilation, but when this balance is disrupted, endothelial dysfunction occurs which can be lead to CVD [43]. A major vasodilator NO is synthesized by nitric oxide synthases [44]. Endothelial dysfunction may occur as a result of decreased eNOS activity or reduced bioavailability of NO [14]. The endothelium also produces vasoconstrictors, such as endothelin and angiotension II. Endothelin is the most potent endogenous vasoconstrictor [43]. As such, in this study, we analyzed vasodilator eNOS and vasoconstrictor ET-1. A previous study showed that NO synthesis inhibited rats had elevated blood pressure [45]. Endemann et al. [14] reported that the eNOS activity of rats fed high-fructose diet decreased in the aorta. In the present study, mRNA expression of eNOS in the abdominal aorta in 45Fat and 30Frc +45 Fat groups was significantly decreased in comparison to those of the other groups. Additionally, the 30Frc group had significantly decreased mRNA expression of eNOS compared to the RD group. ET-1 is an important vasoconstrictor produced by endothelial cells that contributes to enhanced blood pressure $[43,46]$. A previous study reported that rats fed a high-fructose diet for nine weeks had increased ET-1 levels [47]. Similarly, our study showed that the abdominal aortic ET-1 mRNA expression in 30Frc, $45 \mathrm{Fat}$, and 30Frc $+45 \mathrm{Fat}$ groups were significantly higher than the RD group. Our data, together with the previously established literature, suggest that high-fructose diet, as well as the high-fat diet, negatively affected endothelium-derived relaxing and contracting factors. These changes are important factors for the development of hypertension and vascular dysfunction.

\section{Conclusions}

Collectively, the high-fructose diets increased the total-fat weight and serum TG levels in growing rats. Additionally, it had negative effects on abdominal aortic thickness and eNOS, ET-1 mRNA expression.

The strength of our study is that we fed 30\% fructose-diets to the animals. Numerous animal studies have used extreme doses of $\sim 60 \%$ fructose, which, as White [48] suggested, show results that 
are not physiological, and likely cause abnormal metabolism, and therefore cannot be depended on to assess human risk. In the present study we were able to show that $30 \%$ fructose can induce total-fat weight gain, increase aorta wall thickness, and affect eNOS and ET-1 mRNA expression, which are related to CVD risk factors. One potential limitation in the present study was that the sample size was small, which may lessen the significance of the results.

In conclusion, we confirmed high fructose consumption, as well as high fat consumption, in growing rats had negative effects on CVD-related parameters, such as total-fat weight, serum TG, aorta wall thickness, and eNOS, ET-1 mRNA expression of abdominal aorta.

Acknowledgments: This work was supported by Korea Institute of Planning and Evaluation for Technology in Food, Agriculture, Forestry and Fisheries (IPET), funded by Ministry of Agriculture, Food and Rural Affairs (MAFRA) (316055-3).

Author Contributions: The authors' responsibilities were as follows: S.Y. and H.A. designed animal model; S.Y. and H.A. conducted research; S.Y. and Y.K.P. analyzed data; S.Y., H.A., and Y.K.P. drafted and revised the paper; all authors read and approved the final manuscript.

Conflicts of Interest: The authors declare no conflict of interest.

\section{References}

1. Kim, S.D.; Moon, H.; Park, J.S.; Lee, Y.C.; Shin, G.Y.; Jo, H.B.; Kim, B.S.; Kim, J.H.; Chae, Y.Z. Macromineral intake in non-alcoholic beverages for children and adolescents: Using the fourth Korea national health and nutrition examination survey (KNHANES IV, 2007-2009). Korean J. Nutr. 2013, 46, 50-60. [CrossRef]

2. The Korea National Health and Nutrition Examination Survey (KNHNES). Dietary Intake Survey of Infant, Children and Adolescents; The Korea National Health and Nutrition Examination Survey: Cheongju, Korea, 2011.

3. Korea Health Industry Development Institute (KHIDI). In-Depth Analysis on the Dietary Intake Survey of Infant, Children and Adolescents (II); Korea Health Industry Development Institute: Cheongju, Korea, 2010.

4. Bandini, L.G.; Vu, D.; Must, A.; Cyr, H.; Goldberg, A.; Dietz, W.H. Comparison of high-calorie, low-nutrient-dense food consumption among obese and non-obese adolescents. Obes. Res. 1999, 7, 438-443. [CrossRef] [PubMed]

5. Berkey, C.S.; Rockett, H.R.; Field, A.E.; Gillman, M.W.; Colditz, G.A. Sugar-added beverages and adolescent weight change. Obes. Res. 2004, 12, 778-788. [CrossRef] [PubMed]

6. Nakagawa, T.; Hu, H.; Zharikov, S.; Tuttle, K.R.; Short, R.A.; Glushakova, O.; Ouyang, X.; Feig, D.I.; Block, E.R.; Herrera-Acosta, J.; et al. A causal role for uric acid in fructose-induced metabolic syndrome. Am. J. Physiol. Ren. Physiol. 2006, 290, F625-F631. [CrossRef] [PubMed]

7. Mohamed, S.S.; Nallasamy, P.; Muniyandi, P.; Periyasami, V.; Carani, V.A. Genistein improves liver function and attenuates non-alcoholic fatty liver disease in a rat model of insulin resistance. J. Diabetes 2009, 1, 278-287. [CrossRef] [PubMed]

8. Shih, C.; Lin, C.; Lin, W.; Wu, J. Momordica charantia extract on insulin resistance and the skeletal muscle GLUT4 protein in fructose-fed rats. J. Ethnopharmacol. 2009, 123, 82-90. [CrossRef] [PubMed]

9. Bocarsly, M.E.; Powell, E.S.; Avena, N.M.; Hoebel, B.G. High-fructose corn syrup causes characteristics of obesity in rats: Increased body weight, body fat and triglyceride levels. Pharmacol. Biochem. Behav. 2010, 97, 101-106. [CrossRef] [PubMed]

10. Crescenzo, R.; Bianco, F.; Coppola, P.; Mazzoli, A.; Valiante, S.; Liverini, G.; Iossa, S. Adipose tissue remodeling in rats exhibiting fructose-induced obesity. Eur. J. Nutr. 2014, 53, 413-419. [CrossRef] [PubMed]

11. Muniyappa, R.; Montagnani, M.; Koh, K.K.; Quon, M.J. Cardiovascular actions of insulin. Endocr. Rev. 2007, 28, 463-491. [CrossRef] [PubMed]

12. Song, D.; Arikawa, E.; Galipeau, D.; Battell, M.; McNeill, J.H. Androgens are necessary for the development of fructose-induced hypertension. Hypertension 2004, 43, 667-672. [CrossRef] [PubMed]

13. Behr-Roussel, D.; Oudot, A.; Compagnie, S.; Gorny, D.; Le Coz, O.; Bernabe, J.; Wayman, C.; Alexandre, L.; Giuliano, F. Impact of a long-term sildenafil treatment on pressor response in conscious rats with insulin resistance and hypertriglyceridemia. Am. J. Hypertens. 2008, 21, 1258-1263. [CrossRef] [PubMed] 
14. Endemann, D.H.; Schiffrin, E.L. Endothelial dysfunction. J. Am. Soc. Nephrol. 2004, 15, 1983-1992. [CrossRef] [PubMed]

15. Austin, M.A.; King, M.C.; Vranizan, K.M.; Krauss, R.M. Atherogenic lipoprotein phenotype: A proposed genetic marker for coronary heart disease risk. Circulation 1990, 82, 495-506. [CrossRef] [PubMed]

16. De Castro, U.G.; dos Santos, R.A.; Silva, M.E.; de Lima, W.G.; Campagnole-Santos, M.J.; Alzamora, A.C. Age-dependent effect of high-fructose and high-fat diets on lipid metabolism and lipid accumulation in liver and kidney of rats. Lipids Health Dis. 2013, 12. [CrossRef] [PubMed]

17. Yamauchi, T.; Kadowaki, T. Physiological and pathophysiological roles of adiponectin and adiponectin receptors in the integrated regulation of metabolic and cardiovascular diseases. Int. J. Obes. 2008, 32, S13-S18. [CrossRef] [PubMed]

18. Ross, R. The pathogenesis of atherosclerosis: A perspective for the 1990s. Nature 1993, 362, 801-809. [CrossRef] [PubMed]

19. Sinitskaya, N.; Gourmelen, S.; Schuster-Klein, C.; Guardiola-Lemaitre, B.; Pevet, P.; Challet, E. Increasing the fat-to-carbohydrate ratio in a high-fat diet prevents the development of obesity but not a prediabetic state in rats. Clin. Sci. 2007, 113, 417-425. [CrossRef] [PubMed]

20. Matveyenko, A.V.; Gurlo, T.; Daval, M.; Butler, A.E.; Butler, P.C. Successful versus failed adaptation to high-fat diet-induced insulin resistance: The role of IAPP-induced beta-cell endoplasmic reticulum stress. Diabetes 2009, 58, 906-916. [CrossRef] [PubMed]

21. Ouguerram, K.; Nguyen, P. Lipid profile and insulin sensitivity in rats fed with high-fat or high-fructose diets. Br. J. Nutr. 2011, 106, S206-S210.

22. Tran, L.T.; Yuen, V.G.; McNeill, J.H. The fructose-fed rat: A review on the mechanisms of fructose-induced insulin resistance and hypertension. Mol. Cell. Biochem. 2009, 332, 145-159. [CrossRef] [PubMed]

23. Miller, A.; Adeli, K. Dietary fructose and the metabolic syndrome. Curr. Opin. Gastroenterol. 2008, 24, $204-209$. [CrossRef] [PubMed]

24. Angelopoulos, T.J.; Lowndes, J.; Zukley, L.; Melanson, K.J.; Nguyen, V.; Huffman, A.; Rippe, J.M. The effect of high-fructose corn syrup consumption on triglycerides and uric acid. J. Nutr. 2009, 139, 1242S-1245S. [CrossRef] [PubMed]

25. Shulman, G.I. Cellular mechanisms of insulin resistance. J. Clin. Investig. 2000, 106, 171-176. [CrossRef] [PubMed]

26. Blakely, S.R.; Hallfrisch, J.; Reiser, S.; Prather, E.S. Long-term effects of moderate fructose feeding on glucose tolerance parameters in rats. J. Nutr. 1981, 111, 307-314. [PubMed]

27. Tappy, L.; Le, K.A. Metabolic effects of fructose and the worldwide increase in obesity. Physiol. Rev. 2010, 90, 23-46. [CrossRef] [PubMed]

28. Basciano, H.; Federico, L.; Adeli, K. Fructose, insulin resistance, and metabolic dyslipidemia. Nutr. Metab. 2005, 2, 5-20. [CrossRef] [PubMed]

29. Iida, T.; Yamada, T.; Hayashi, N.; Okuma, K.; Izumori, K.; Ishii, R.; Matsuo, T. Reduction of abdominal fat accumulation in rats by 8 -week ingestion of a newly developed sweetener made from high fructose corn syrup. Food Chem. 2013, 138, 781-785. [CrossRef] [PubMed]

30. Catena, C.; Giacchetti, G.; Novello, M.; Colussi, G.; Cavarape, A.; Sechi, L.A. Cellular mechanisms of insulin resistance in rats with fructose-induced hypertension. Am. J. Hypertens. 2003, 16, 973-978. [CrossRef]

31. Kho, M.C.; Lee, Y.J.; Ahn, Y.M.; Choi, Y.H.; Kim, A.Y.; Kang, D.G.; Lee, H.S. Effects of ethanol extract of gastrodia elata blume on high-fructose induced metabolic syndrome. FASEB J. 2013, 27, 1108-1113.

32. Dandona, P.; Aljada, A.; Bandyopadhyay, A. Inflammation: The link between insulin resistance, obesity and diabetes. Trends Immunol. 2004, 25, 4-7. [CrossRef] [PubMed]

33. Fantuzzi, G. Adipose tissue, adipokines, and inflammation. J. Allergy Clin. Immunol. 2005, 115, 911-999. [CrossRef] [PubMed]

34. Rudin, E.; Barzilai, N. Inflammatory peptides derived from adipose tissue. Immun. Ageing 2005, 2. [CrossRef] [PubMed]

35. Yudkin, J.S.; Stehouwer, C.D.; Emeis, J.J.; Coppack, S.W. C-reactive protein in healthy subjects: Associations with obesity, insulin resistance, and endothelial dysfunction: A potential role for cytokines originating from adipose tissue? Arterioscler. Thromb. Vasc. Biol. 1999, 19, 972-978. [CrossRef] [PubMed] 
36. Davis, P.H.; Dawson, J.D.; Riley, W.A.; Lauer, R.M. Carotid intimal-medial thickness is related to cardiovascular risk factors measured from childhood through middle age: The Muscatine study. Circulation 2001, 104, 2815-2819. [CrossRef] [PubMed]

37. Berenson, G.S.; Srinivasan, S.R.; Bao, W.; Newman, W.P.; Tracy, R.E.; Wattigney, W.A. Association between multiple cardiovascular risk factors and atherosclerosis in children and young adults. N. Engl. J. Med. 1998, 338, 1650-1656. [CrossRef] [PubMed]

38. McGill, H.C., Jr.; McMahan, C.A.; Zieske, A.W.; Malcom, G.T.; Tracy, R.E.; Strong, J.P. Effects of nonlipid risk factors on atherosclerosis in youth with a favorable lipoprotein profile. Circulation 2001, 103, 1546-1550. [CrossRef] [PubMed]

39. McGill, H.C., Jr.; McMahan, C.A.; Herderick, E.E.; Tracy, R.E.; Malcom, G.T.; Zieske, A.W.; Strong, J.P. Effects of coronary heart disease risk factors on atherosclerosis of selected regions of the aorta and right coronary artery. Arterioscler. Thromb. Vasc. Biol. 2000, 20, 836-845. [CrossRef] [PubMed]

40. Bonetti, P.O.; Lerman, L.O.; Lerman, A. Endothelial dysfunction: A marker of atherosclerotic risk. Arterioscler. Thromb. Vasc. Biol. 2003, 23, 168-175. [CrossRef] [PubMed]

41. Pepine, C.J. Clinical implications of endothelial dysfunction. Clin. Cardiol. 1998, 21, 795-799. [CrossRef] [PubMed]

42. Brunner, H.; Cockcroft, J.R.; Deanfield, J.; Donald, A.; Ferrannini, E.; Halcox, J.; Kiowski, W.; Lüscher, T.F.; Mancia, G.; Natali, A. Endothelial function and dysfunction. Part II: Association with cardiovascular risk factors and diseases. A statement by the working group on endothelins and endothelial factors of the european society of hypertension. J. Hypertens. 2005, 23, 233-246. [CrossRef] [PubMed]

43. Davignon, J.; Ganz, P. Role of endothelial dysfunction in atherosclerosis. Circulation 2004, 109, $27-32$. [CrossRef] [PubMed]

44. Dawson, V.; Brahmbhatt, H.; Mong, J.; Dawson, T. Expression of inducible nitric oxide synthase causes delayed neurotoxicity in primary mixed neuronal-glial cortical cultures. Neuropharmacology 1994, 33, 1425-1430. [CrossRef]

45. Rees, D.D.; Palmer, R.M.; Moncada, S. Role of endothelium-derived nitric oxide in the regulation of blood pressure. Proc. Natl. Acad. Sci. USA 1989, 86, 3375-3378. [CrossRef] [PubMed]

46. Oliver, F.J.; de la Rubia, G.; Feener, E.P.; Lee, M.E.; Loeken, M.R.; Shiba, T.; Quertermous, T.; King, G.L. Stimulation of endothelin-1 gene expression by insulin in endothelial cells. J. Biol. Chem. 1991, 266, 23251-23256. [PubMed]

47. Verma, S.; Bhanot, S.; McNeill, J.H. Effect of chronic endothelin blockade in hyperinsulinemic hypertensive rats. Am. J. Physiol. 1995, 269, H2017-H2021. [PubMed]

48. White, J.S. Challenging the fructose hypothesis: New perspectives on fructose consumption and metabolism. Adv. Nutr. 2013, 4, 246-256. [CrossRef] [PubMed]

(C) 2016 by the authors; licensee MDPI, Basel, Switzerland. This article is an open access article distributed under the terms and conditions of the Creative Commons Attribution (CC-BY) license (http://creativecommons.org/licenses/by/4.0/). 